\title{
Avaliação quantitativa de monoepoxiácidos, monocetoácidos e monohidroxiácidos em óleos e gorduras provenientes de fritura descontínua de batatas
}

\author{
Quantitative evaluation of monoepoxyacids, monoketoacids and monohydroxyacids \\ in fats and oils used in discontinuous frying of potatoes
}

\section{Eliana Rodrigues MACHADO ${ }^{\star *}$, Susana MARMESAT ${ }^{2}$, María del Carmen DOBARGANES ${ }^{2}$, Shirley ABRANTES ${ }^{1}$}

\begin{abstract}
Resumo
$\mathrm{Na}$ fritura, os óleos e gorduras sofrem degradação formando os compostos polares, como os triacilgliceróis polimerizados e os monômeros de triacilgliceróis oxidados, estes últimos têm sido relacionados a patologias e se constituem de grupos como os monoepoxiácidos, monocetoácidos e monohidroxiácidos. Foram determinados os teores destes três grupos de substâncias, através da análise cromatográfica a gás dos ésteres metílicos de ácidos graxos após derivação a frio das amostras e concentração posterior das substâncias de interesse mediante extração em fase sólida, e os teores dos ácidos graxos polares polimerizados, utilizando a combinação das técnicas cromatográficas de adsorção em coluna e por exclusão, em gordura de soja parcialmente hidrogenada e óleos de soja e de palma, aquecidos a $180{ }^{\circ} \mathrm{C}$ por 25 horas, provenientes de experimentos de fritura. Foram encontrados teores de 3,30 a 8,24; 1,51 a 4,32 e 3,42 a 8,71 mg.g-1 de monoepoxiácidos, monocetoácidos e monohidroxiácidos, respectivamente, nas amostras com níveis de compostos polares de 20,8 a 44,1\% (m/m), e predominância de formação de polímeros. Os resultados sugeriram que óleos e gorduras monoinsaturados apresentam maior tendência à formação de monômeros oxidados e menor tendência à formação de polímeros, ao contrário dos óleos poliinsaturados.

Palavras-chave: compostos polares; monocetoácidos; monoepoxiácidos; monohidroxiácidos; óleos de fritura; polímeros.
\end{abstract}

\begin{abstract}
During frying, fats and oils undergo degradation with the formation of polar compounds. Among these are polymeric triglycerides, as well as oxidized monomeric triglycerides. The last group has been related to several diseases and contains groups including epoxy, keto and hydroxy groups of importance from a quantitative point of view. In this study, monoepoxyacids, monoketoacids and monohydroxyacids were quantified in partially hydrogenated soybean oil, soybean oil and palm oil, after heating for 25 hours, at $180^{\circ} \mathrm{C}$, in frying experiments. The determination was carried out by gas chromatography after fat derivatization to fatty acid methyl esters at room temperature and concentration of the compounds of interest by solid phase extraction on silica cartridges. Quantitative analyses of polar fatty acids were also obtained by combination of adsorption and size exclusion chromatography. The major content corresponded to polymeric compounds. Amounts ranging from 3.30 to 8.24 ; from 1.51 to 4.32 and from 3.42 to $8.71 \mathrm{mg} \cdot \mathrm{g}^{-1}$ were found for monoepoxyacids, monoketoacids and monohydroxyacids, respectively, for samples containing polar compounds between 20.8 and $44.1 \%$. The results suggested that monounsaturated oils have a higher tendency to the formation of oxidized monomers while polyunsaturated oils have a higher tendency to the formation of polymers.

Keywords: epoxy fatty acids; frying oils; hydroxy fatty acids; keto fatty acids; polar compounds; polymers.
\end{abstract}

\section{Introdução}

A fritura é um meio de preparo de alimentos bastante utilizado em todo o mundo. Neste processo o óleo ou gordura é submetido a altas temperaturas na presença de ar e de água. Esta condição propicia a formação de um número considerável de substâncias oriundas de reações térmicas, oxidativas e hidrolíticas (CHANG; PETERSON; HO, 1978; DOBARGANES; PÉREZ-CAMINO; MÁRQUEZ-RUÍZ, 1988; GASPAROLI, 1998; JORGE et al., 1996; MÁRQUEZ-RUIZ; TASIOULA-MARGARI; DOBARGANES, 1995; NAWAR, 1998; SCHWARTZ; RADY; CASTAÑEDA, 1994; VELASCO et al., 2004b). As reações hidrolíticas liberam substâncias como diacilgliceróis e ácidos graxos livres, e as reações térmicas e oxidativas formam um grande número de substâncias como triacilgliceróis dimerizados e polimerizados e monômeros de triacilgliceróis oxidados (VELASCO et al., 2004b).

Estes grupos de substâncias constituem os compostos polares (AOAC, 2003). Neste sentido, legislações de muitos países preconizam para óleos e gorduras usados em frituras o valor máximo de $25 \%, \mathrm{~m} / \mathrm{m}$ do óleo, em compostos polares (DANA; SAM SAGUY, 2001).

A alteração tanto quantitativa quanto qualitativa destes óleos ou gorduras depende de um número elevado de variáveis entre elas, a que está relacionada com a adição de óleo novo

Recebido para publicação em 25/5/2007

Aceito para publicação em 28/11/2007 (002555)

Fundação Oswaldo Cruz - FIOCRUZ, Instituto Nacional de Controle de Qualidade em Saúde - INCQS, Av. Brasil, 4365, Manguinhos, CEP 21040-900, Rio de Janeiro - RJ,

Brasil, E-mail: eliana.machado@incqs.fiocruz.br

${ }^{2}$ Consejo Superior de Investigaciones Científicas - CSIC, Instituto de la Grasa, Av. Padre García Tejero, 4, 41012, Sevilla, España

${ }^{*}$ A quem a correspondência deve ser enviada 
para compensar o absorvido pelo alimento (JORGE, 1996; ROMERO et al., 1998). O tempo determinado para se adicionar óleo novo para repor o que foi perdido é denominado período de reposição. Períodos de reposição elevados, característicos de frituras descontínuas, são mais utilizados em restaurantes e lanchonetes e permitem uma alteração maior do que as frituras contínuas, mais utilizadas em indústrias alimentícias, que apresentam períodos de reposição curtos (JORGE, 1996; JORGE et al., 1996).

Em análises de amostras de óleos/gorduras em uso em frituras coletadas nos setores de restaurantes e lanchonetes pelos serviços de inspeção de diversos países, foram encontradas porcentagens acima de $30 \%$ de amostras fora do limite permitido para uso, segundo leis internacionais (SAM SAGUY; DANA, 2003).

A determinação quantitativa de ácidos graxos polares e suas frações em óleos e gorduras usados em frituras em torno do limite de rejeição (25\%) mostraram que os triacilgliceróis dimerizados e polimerizados foram predominantemente formados em relação aos monômeros de triacilgliceróis oxidados e que quantidades destes foram formadas em torno de $30 \mathrm{mg} . \mathrm{g}^{-1}$ do óleo (MÁRQUEZ-RUIZ; TASIOULA-MARGARI; DOBARGANES, 1995). Outros estudos também demonstraram maior formação de dímeros e polímeros em relação aos monômeros oxidados, quando consideráveis níveis de degradação das amostras estavam presentes, em sistemas modelo de ésteres metílicos dos ácidos oléico e linoléico termoxidados a $180{ }^{\circ} \mathrm{C}$ (BERDEAUX; MÁRQUEZ-RUÍZ; DOBARGANES, 1999); em óleos de oliva e de girassol termoxidados a $180^{\circ} \mathrm{C}$, e em óleos e gorduras usados em fritura (VELASCO et al., 2004a).

Das substâncias provenientes da oxidação de óleos e gorduras, o grupo dos monômeros dos triacilgliceróis oxidados é de grande importância do ponto de vista nutricional pelo seu alto grau de hidrólise pela lipase pancreática, alta absorção em cobaias dos ácidos graxos oxidados liberados pela enzima, e presença em níveis consideráveis em óleos e gorduras de fritura (MÁRQUEZ-RUÍZ; GUEVEL; DOBARGANES, 1998; MÁRQUEZ-RUİZ; PÉREZ-CAMINO; DOBARGANES, 1992; MÁRQUEZ-RUIZ; TASIOULA-MARGARI; DOBARGANES, 1995; MÁRQUEZ-RUIZ; DOBARGANES, 1995). Fazem parte desta fração, triacilgliceróis com diferentes grupos funcionais contendo oxigênio como: hidroperóxido, aldeído, cetona, hidróxido e epóxido (FRANKEL, 1998).

Os monoepoxiácidos têm sido determinados quantitativamente e considerados como principal grupo da fração dos monômeros oxidados, em termos quantitativos, em sistemas modelo de triacilgliceróis; em óleos de oliva e de girassol termoxidados; e em óleos usados em frituras (BERDEAUX; MÁRQUEZ-RUÍZ; DOBARGANES, 1999; VELASCO et al., 2002; VELASCO et al., 2004a).

Teores em níveis de até $260 \mu$ moles. $\mathrm{g}^{-1}$ do óleo de cetoácidos, determinados como 2,4-dinitrofenilhidrazonas; e de hidroxi e polihidroxiácidos, determinados como derivados da 2,6-dinitrofenilhidrazona do éster do ácido pirúvico foram obtidos nos óleos de oliva e de açafrão, e em gordura animal, termoxidados a $180^{\circ} \mathrm{C}$ por até 72 horas (SCHWARTZ; RADY; CASTAÑEDA, 1994).

Com relação a efeitos tóxicos dos epóxidos e hidróxidos de ácidos graxos, estudos demonstraram que os monoepóxidos do ácido linoléico e seus metabólitos (dióis) estão relacionados à necrose tissular em pacientes com queimaduras severas (KOSAKA et al., 1994); e ao mecanismo de lesão aguda do pulmão em humanos (TOTANI, 2000). Também apresentou citotoxicidade em sistema teste do túbulo renal de coelho (MORAN et al., 2000); e em camundongos sugeriu-se o 9,10-epoxi-12-octadecenoato como mediador tóxico na síndrome da angústia respiratória aguda (SARA) (ZHENG et al., 2001). Em estudos in vitro, Greene et al. (2000) verificaram em células Sf-21, células do inseto Spodoptera frugiperda, que os ésteres metílicos de monoepóxidos de ácidos graxos de cadeia longa e seus metabólitos diós foram potentes pró-toxinas. Em outro estudo de citotoxicidade, realizado em células Sf-21 Mitchell, Moran e Grant (2002) demonstraram a citotoxicidade do cis-monoepóxido e do dihidróxido do ácido linoléico na ausência de albumina, e citotoxicidade do dihidróxido na presença de albumina.

A absorção de epóxidos e de hidróxidos de ácidos graxos marcados, na forma de triacilgliceróis, foi recentemente relatada em humanos (WILSON et al., 2002a; WILSON, 2002b), verificando que os monoepóxidos e os monohidróxidos foram mais absorvidos do que os diepóxidos e dihidróxidos.

Portanto estudos adicionais de absorção, de obtenção de teores, e também de avaliação toxicológica dos grupos dos epoxiácidos, cetoácidos e hidroxiácidos em óleos e gorduras usados em frituras, são requeridos para contribuir com estudos futuros de avaliação de risco dos alimentos fritos.

O objetivo deste trabalho foi determinar quantitativamente os grupos de monoepoxiácidos, monocetoácidos e monohidroxiácidos e avaliar seus resultados em gordura vegetal parcialmente hidrogenada, óleo de soja e óleo de palma, provenientes de fritura descontínua de batatas.

\section{Material e métodos}

\subsection{Amostras iniciais - não aquecidas}

A gordura de soja parcialmente hidrogenada e o óleo de soja, utilizados para fins culinários, foram obtidos do comércio da cidade do Rio de Janeiro, e estavam dentro do prazo de validade.

O óleo de palma refinado, comercializado para fritura, foi obtido por doação da indústria Grupo Agropalma da cidade de Tailândia, Pará, com certificado de análise e data de validade adequada.

\subsection{Amostras provenientes dos experimentos de fritura descontínua de batatas}

Foram utilizadas seis amostras, duas de cada óleo/gordura referidas acima, provenientes dos experimentos de fritura.

Cada experimento foi realizado no laboratório, de acordo com Jorge et al. (1996) e consistiu de operações de fritura: 
$(100 \pm 0,01) \mathrm{g}$ de batatas frescas descascadas, cortadas em palito, lavadas e secas foram fritas em $(550 \pm 0,01) \mathrm{g}$ de óleo na temperatura de $(183,1 \pm 1,7)^{\circ} \mathrm{C}$, por 3 minutos. Foram utilizadas três fritadeiras elétricas domésticas semelhantes de $1 \mathrm{~L}$, da marca Taurus, Gourmet de Taurus, Barcelona, Espanha, com relação inicial de superfície da fritadeira sobre volume do meio de fritura de $0,3 \mathrm{~cm}^{-1}$. Cada experimento foi realizado em cinco dias seguidos, e o óleo foi submetido a 5 horas de aquecimento por dia ocorrendo neste período a operação de fritura. Não houve reposição ou substituição do meio de fritura. Ao final de cada experimento, com 25 horas de aquecimento, as amostras foram coletadas e estocadas à temperatura de $-20^{\circ} \mathrm{C}$, até o momento das análises. Os experimentos foram feitos em duplicata para cada óleo/gordura.

\subsection{Reagentes}

Foram utilizados solventes e reagentes de grau P.A., com exceção dos solventes éter etílico, hexano e tetrahidrofurano, de qualidade para análise de resíduos.

O gel de sílica 60, para cromatografia em coluna, com tamanho de partícula de 0,063-0,100 mm, foi adquirido da Merck, Darmstadt, Germany.

As colunas Sep Pak ${ }^{\oplus}$ Vac de sílica $6 \mathrm{cc}, 1,0 \mathrm{~g}$, foram adquiridas da Waters Associates, Milford, MA, USA.

\subsection{Substâncias padrão}

Os ésteres metílicos dos ácidos graxos: cis-9,10-epoxiesteárico e trans-9,10-epoxiesteárico foram obtidos da Sigma-Aldrich Chemie GmbH, Steinhein, Germany; os ésteres metílicos 12-cetoesteárico e 12-hidroxiesteárico foram obtidos da Nu-Chek-Prep, Elysian, MN, USA.

Os ésteres metílicos dos ácidos graxos: láurico, mirístico, palmítico, esteárico, oléico, linoléico, linolênico, araquídico, behênico, lignocérico e heneicosanóico foram obtidos da SigmaAldrich Chemie GmbH, Steinhein, Germany.

\subsection{Métodos analíticos}

As seguintes determinações foram efetuadas, em duplicata, para cada amostra inicial, de acordo com o método da International Union of Pure and Applied Chemistry-IUPAC (IUPAC, 1992): acidez em ácido oléico, $\%, \mathrm{~m} / \mathrm{m}$, método 2.201 ; índice de peróxidos, meq $\mathrm{O}_{2} / \mathrm{kg}$, método 2.501 ; matéria insaponificável, $\%, \mathrm{~m} / \mathrm{m}$, método 2.401 e determinação da composição percentual, $\mathrm{m} / \mathrm{m}$, dos ácidos graxos, métodos 2.301 e 2.302. O primeiro e o segundo método utilizam a técnica de volumetria; o terceiro método utiliza extração por solvente orgânico e gravimetria.

A determinação da composição percentual, m/m, dos ácidos graxos foi realizada através da análise cromatográfica a gás dos ésteres metílicos destes ácidos, obtidos a partir da dissolução de $(50 \pm 0,0001) \mathrm{mg}$ da amostra em $1 \mathrm{~mL}$ de hexano e posterior derivação com adição de duas gotas da solução de $\mathrm{KOH} 2 \mathrm{M}$ em metanol. Utilizou-se um cromatógrafo da Hewlett-Packard, modelo 6890, Avondale, PA, USA, equipado com detector por ionização em chama; injetor automático marca Agilent, Agilent Technologies, Karlsruhe, Germany com divisão de fluxo; e coluna cromatográfica, de alta resolução de sílica fundida, da Hewlett-Packard, Avondale, PA, USA, com fase estacionária de polietilenoglicol, nas dimensões de $60 \mathrm{~m}$ de comprimento; $0,25 \mathrm{~mm}$ de diâmetro interno e $0,25 \mu \mathrm{m}$ de espessura de fase estacionária. As seguintes condições cromatográficas foram adotadas: temperatura da coluna: $200{ }^{\circ} \mathrm{C}$ ( 2 minutos) $/ 2{ }^{\circ} \mathrm{C} /$ minuto $/ 240{ }^{\circ} \mathrm{C}$ (30 minutos); temperatura do detector e do injetor: $250{ }^{\circ} \mathrm{C}$; fluxo do gás carreador $\left(\mathrm{H}_{2}\right)$ : 1,0 mL/minuto; razão de divisão de fluxo: 40,0:1; fluxo do gás auxiliar $\left(\mathrm{N}_{2}\right): 45,0 \mathrm{~mL} /$ minuto; fluxo do $\mathrm{H}_{2}: 40,0 \mathrm{~mL} /$ minuto; fluxo do ar sintético: $450,0 \mathrm{~mL} /$ minuto; volume injetado da amostra: $1,0 \mu \mathrm{L}$.

A identificação dos picos realizou-se através da comparação dos tempos de retenção dos padrões dos ésteres metílicos dos ácidos graxos de interesse.

A porcentagem de cada ácido graxo presente na amostra foi obtida a partir da divisão da área do pico cromatográfico do ácido graxo pela soma das áreas de todos os ácidos graxos da amostra multiplicada por 100 .

A determinação quantitativa de compostos polares foi realizada através da cromatografia de adsorção em coluna, segundo o método oficial da IUPAC 2.507 (IUPAC, 1992), utilizando a mistura éter de petróleo: éter etílico (90:10) como solvente de eluição da fração não polar.

A determinação quantitativa dos ésteres metílicos de ácidos graxos (EMAG) polares e das suas frações, monômeros oxidados e polímeros, foi obtida segundo Márquez-Ruíz; Pérez-Camino e Dobarganes (1990), através das etapas:

- Transmetilação de $(500 \pm 0,0001) \mathrm{mg}$ da amostra com metóxido de sódio metanólico 0,2 M e neutralização com metanol sulfúrico $1 \mathrm{M}$;

- Separação dos ésteres metílicos obtidos em duas frações de diferentes polaridades, por cromatografia de adsorção em coluna. A fração não polar foi eluída com a mistura hexano: éter etílico (95:5), e a fração polar foi eluída com éter etílico; e

- A fração polar obtida foi evaporada e dissolvida em hexano à concentração de 20 a $25 \mathrm{mg} \cdot \mathrm{mL}^{-1}$, e a seguir foi analisada por cromatografia por exclusão. Foram utilizados um injetor Rheodyne $7725 \mathrm{i}$ com loop de $20 \mu \mathrm{L}$; uma bomba Waters 510, da Waters Associates, Milford, MA, USA; duas colunas cromatográficas, da Waters Associates, Milford, MA, USA, conectadas em série, de 100 e $500 \AA$, com dimensões de $30 \mathrm{~cm}$ de comprimento e $0,77 \mathrm{~cm}$ de diâmetro interno, cada uma, empacotada com copolímero, com ligações cruzadas, de estireno divinilbenzeno, com tamanho de partícula de $5 \mu \mathrm{m}$; e detector de índice de refração modelo L-7490 da Merck-La Chrom, Darmstadt, Germany. Foram injetados, em condições isocráticas, $10 \mu \mathrm{L}$ da amostra em um fluxo de $1,5 \mathrm{~mL} /$ minuto de tetrahidrofurano utilizado como fase móvel.

A identificação dos picos dos ésteres metílicos de monômeros oxidados e de polímeros foi realizada através da comparação 
do cromatograma obtido com o perfil cromatográfico padronizado pelo método analítico utilizado (MÁRQUEZ-RUÍZ; PÉREZ-CAMINO; DOBARGANES, 1990).

O teor, em porcentagem, dos picos de interesse, foi calculado pela razão entre a área de cada pico e a soma das áreas de todos os picos apresentados, multiplicada por 100.

A determinação quantitativa dos ésteres metílicos de monoepoxiácidos, monocetoácidos e monohidroxiácidos foi realizada por análise cromatográfica a gás de alta resolução, de acordo com Marmesat (2007) (em fase de elaboração)․․

Procedimento de transmetilação: à temperatura ambiente $(100 \pm 0,0001) \mathrm{mg}$ da amostra foram pesados em um tubo com tampa de rosca. Foram adicionados $3 \mathrm{~mL}$ de éter tert-butil metilíco e 1,5 mL de solução de metóxido de sódio em metanol a 0,2 M. O tubo foi agitado em agitador mecânico por 1 minuto, e a seguir, deixado em repouso por 2 minutos. Adicionaram-se 2 gotas de solução alcoólica a $1 \%$ de fenolftaleína, e se neutralizou com solução de metanol sulfúrico $0,1 \mathrm{M}$. O tubo foi agitado mecanicamente. A seguir, foram adicionados $3 \mathrm{~mL}$ de água destilada e a solução foi centrifugada a $5000 \mathrm{rpm}$ por 1 minuto. A fase orgânica foi separada e evaporada à secura, em banho-maria à temperatura inferior a $40^{\circ} \mathrm{C}$ e leve corrente de nitrogênio.

Separação em duas frações de diferentes polaridades: $(50 \pm 0,0001) \mathrm{mg}$ dos ésteres metílicos obtidos acima foram dissolvidos em $2 \mathrm{~mL}$ da mistura de hexano: éter etílico (98:2) e submetidos à separação em coluna Sep-Pak ${ }^{\oplus}$, previamente condicionada com $10 \mathrm{~mL}$ da mistura de solventes mencionada acima, utilizando para a eluição da fração não polar $25 \mathrm{~mL}$ da mesma mistura de solventes. E para a eluição da fração polar, foram utilizados $25 \mathrm{~mL}$ de éter etílico. À fração polar, que contém as substâncias de interesse, se adicionou $1 \mathrm{~mL}$ de solução do padrão interno, éster metílico do ácido heneicosanóico, a $0,3 \mathrm{mg} \cdot \mathrm{mL}^{-1}$ de hexano. Esta fração foi evaporada à secura, em evaporador rotativo a vácuo à temperatura inferior a $40^{\circ} \mathrm{C}$. A seguir, o resíduo foi dissolvido em $2 \mathrm{~mL}$ de metanol e mantido em corrente de hidrogênio à temperatura ambiente por 10 minutos em presença de óxido de platina como catalisador. A amostra hidrogenada foi filtrada com poros de $0,2 \mu \mathrm{m}$ e lavada com $5 \mathrm{~mL}$ de éter etílico, e então evaporada à secura sob leve corrente de nitrogênio em banho-maria à temperatura inferior a $40{ }^{\circ} \mathrm{C}$. O resíduo obtido foi redissolvido em $500 \mu \mathrm{L}$ de éter etílico, e $2 \mu \mathrm{L}$ da solução foram injetados no cromatógrafo a gás. As condições de análises cromatográficas foram as mesmas utilizadas para a determinação da composição de ácidos graxos, descrita acima.

Os grupos dos ésteres metílicos oxidados (monoepoxiácidos, monocetoácidos e monohidroxiácidos) foram identificados mediante cromatografia a gás acoplada à espectrometria de massas com a ajuda dos padrões disponíveis (BERDEAUX et al., 1999; MARMESAT, 2007 (em fase de elaboração) ${ }^{1}$; VELASCO et al., 2002; VELASCO et al., 2004a). O equipamento utilizado foi um espectrômetro de massas Finnigan MAT95's, operando

\footnotetext{
${ }^{1}$ Aceites de girasol modificados geneticamente: Comportamiento a elevada temperatura y formación de nuevos compuestos, de autoria de Susana Marmesat (Tese de doutorado) Universidad de Sevilla, Sevilha, Espanha, a ser defendida em 2007.
}

no modo de ionização eletrônica $(70 \mathrm{eV})$ acoplado a um cromatógrafo a gás Carlo Erba GC série 8000. Os espectros foram adquiridos em uma faixa de 28-600 a.m.u.. As condições de análises cromatográficas foram as mesmas utilizadas para a determinação da composição de ácidos graxos.

Os teores (mg.g $\mathrm{g}^{-1}$ do óleo/gordura) dos ésteres metílicos dos monoepoxiádos (EPOXI), monocetoácidos (CETO) e monohidroxiácidos (HIDROXI) foram obtidos através das Equações 1, 2 e 3:

Teor de EPOXI (mg.g $\left.\mathrm{g}^{-1}\right)=\sum \mathrm{A}_{\mathrm{EPOXI}} \times \mathrm{PI} \times \mathrm{Fc} / \mathrm{A}_{\mathrm{PI}} \times \mathrm{M}$

Teor de HIDROXI $\left(\mathrm{mg} \cdot \mathrm{g}^{-1}\right)=\sum \mathrm{A}_{\text {HIDROXI }} \times \mathrm{PI} \times \mathrm{Fc} / \mathrm{A}_{\mathrm{PI}} \times \mathrm{M}$

Teor de CETO $\left(\mathrm{mg} \cdot \mathrm{g}^{-1}\right)=\sum \mathrm{A}_{\text {СETO }} \times \mathrm{PI} \times \mathrm{Fc} / \mathrm{A}_{\mathrm{PI}} \times \mathrm{M}$

em que:

$\sum \mathrm{A}_{\mathrm{EPOXI}}$ somatório das áreas dos picos das substâncias do grupo dos EPOXI;

$\sum \mathrm{A}_{\text {HIDROXI }}$ somatório das áreas dos picos das substâncias do grupo dos HIDROXI;

$\sum \mathrm{A}_{\text {СЕтO }}$ somatório das áreas dos picos das substâncias do grupo dos CETO;

PI concentração em mg. $\mathrm{g}^{-1}$ do padrão interno;

$\mathrm{A}_{\mathrm{PI}}$ área do padrão interno;

Fc fator de correção para os monoepoxiácidos $=1,21$; para os monocetoácidos $=1,20$ e para os monohidroxiácidos $=1,18$. Os fatores de correção foram calculados previamente de soluções com concentrações conhecidas do padrão interno e dos ésteres metílicos de cis-9,10-epoxiesteárico, 12-cetoesteárico e 12-hidroxiesteárico; e

M massa em g da amostra.

A eficiência de cada etapa de separação em cromatografia em coluna, utilizada nos métodos analíticos deste estudo, foi verificada através da cromatografia em camada delgada utilizando a mistura hexano: éter etílico: ácido acético (80:20:1, $\mathrm{v} / \mathrm{v} / \mathrm{v}$ ) como solvente de desenvolvimento da placa. E para a revelação das manchas, a placa foi exposta a vapores de iodo (MÁRQUEZ-RUÍZ; PÉREZ-CAMINO; DOBARGANES, 1990).

O teor, $\%, \mathrm{~m} / \mathrm{m}$, de lipídios da batata frita foi obtido a partir de $(20 \pm 0,01) \mathrm{g}$ da batata frita que depois de liofilizada e triturada foi submetida à extração dos lipídios com três alíquotas de 60 $\mathrm{mL}$ da mistura éter etílico: hexano (1:1). A mistura foi submetida à agitação por 10 minutos a cada adição do dissolvente. O extrato lipídico obtido foi filtrado com sulfato de sódio anidro para balão. Evaporou-se a mistura de dissolventes em evaporador rotativo a vácuo. $\mathrm{O}$ resíduo foi transferido quantitativamente para tubo de $10 \mathrm{~mL}$ anteriormente pesado. Este resíduo foi evaporado à secura, em banho-maria, à temperatura inferior a $40{ }^{\circ} \mathrm{C}$ sob leve corrente de nitrogênio, e a seguir resfriado e pesado. Repetiram-se as operações de evaporação, resfriamento e pesagem, até peso constante. 


\section{Resultados e discussão}

Os dados da Tabela 1 mostram que as amostras iniciais apresentaram, conforme as análises específicas, características de identidade e qualidade adequadas ao estudo (BRASIL, 2005).

A Tabela 2 mostra os resultados encontrados para os compostos polares e para a fração dos EMAG polares, grupo dos ésteres dos ácidos graxos com cadeias acil alteradas; e sua distribuição em polímeros e monômeros oxidados, em gordura de soja parcialmente hidrogenada, óleo de soja e óleo de palma, aquecidos a $180{ }^{\circ} \mathrm{C}$ por 25 horas, provenientes de experimentos de frituras descontínuas de batatas. Pode-se observar que em todos os experimentos do estudo houve predominância da formação de polímeros em relação aos monômeros oxidados. Estes resultados estão de acordo com Márquez-Ruíz, Tasioula-Margari e Dobarganes (1995), que encontraram maior concentração de polímeros em relação a outros grupos de substâncias, na fração dos compostos polares formados em óleos e gorduras usados em frituras com limite de rejeição em torno de $25 \%$ de compostos polares. Velasco et al. (2004a) também encontraram teores significativos de polímeros em maiores quantidades do que os monômeros oxidados em óleos e gorduras usados em frituras em restaurantes e lanchonetes da Espanha, com valores consideráveis de degradação.

Também se verifica, na Tabela 2, que para níveis similares de ácidos graxos polares, a gordura vegetal e o óleo de palma, óleo/ gordura do grupo de ácidos graxos monoinsaturados, apresentaram conteúdos mais baixos de polímeros do que o óleo de soja, que apresenta predominância de ácidos graxos poliinsaturados. Estes resultados estão de acordo com Velasco et al. (2004a), que em estudo com óleos termoxidados, de oliva, do grupo dos monoinsaturados e de girassol, do grupo dos poliinsaturados, e com óleos e gorduras usados em frituras descontínuas do comércio, concluíram que óleos do grupo de ácidos graxos monoinsaturados apresentam menor tendência à polimerização do que óleos do grupo de ácidos graxos poliinsaturados; e com Berdeaux, Márquez-Ruíz e Dobarganes (1999), que verificaram maior formação de polímeros a partir dos ésteres metílicos do ácido linoléico (poliinsaturado) do que a partir dos ésteres metílicos do ácido oléico (monoinsaturado).

Também se observa, na Tabela 2, como esperado, que a formação de ácidos graxos das frações dos monômeros oxidados e dos polímeros aumentou com o aumento do nível da degradação (nível de ácidos graxos polares totais).

A Figura 1 mostra a parte significativa do gráfico da análise cromatográfica a gás, com o pico do padrão interno adicionado, éster metílico do ácido heneicosanóico (C21:0) e os grupos dos monoepoxiácidos, monocetoácidos e monohidroxiácidos.

Foram determinados como monoepoxiácidos, monocetoácidos e monohidroxiácidos a soma dos picos cromatográficos que aparecem nas regiões definidas.

A hidrogenação da amostra na última etapa do procedimento analítico origina a concentração dos ácidos oxidados presentes (monoinsaturados, diinsaturados, nos óleos/gordura, e triinsaturados, na gordura vegetal e no óleo de soja), pois são

Tabela 1. Características de qualidade e identidade da gordura vegetal parcialmente hidrogenada, do óleo de soja e do óleo de palma.

\begin{tabular}{|c|c|c|c|c|}
\hline & & Gordura hidrogenada & Óleo de soja & Óleo de palma \\
\hline Acidez em ácido oléico $^{1}(\%, \mathrm{~m} / \mathrm{m})$ & & $0,09 \pm 0,03$ & $0,07 \pm 0,0$ & $0,08 \pm 0,01$ \\
\hline Índice de peróxidos ${ }^{1}\left(\right.$ meq $\left._{2} / \mathrm{kg}\right)$ & & $0,56 \pm 0,07$ & $0,67 \pm 0,01$ & $2,70 \pm 0,09$ \\
\hline Estabilidade oxidativa $^{1}(\mathrm{~h})$ & & $17,7 \pm 1,0$ & $7,6 \pm 0,5$ & $47,9 \pm 2,2$ \\
\hline Matéria insaponificável ${ }^{1}(\%, \mathrm{~m} / \mathrm{m})$ & & $0,75 \pm 0,04$ & $0,63 \pm 0,01$ & $0,49 \pm 0,09$ \\
\hline \multirow[t]{3}{*}{ Ácidos $\operatorname{graxos}^{1}(\%, \mathrm{~m} / \mathrm{m})$} & C $16: 0$ & $11,3 \pm 0,4$ & $11,3 \pm 0,1$ & $42,3 \pm 0,5$ \\
\hline & C 18:0 & $9,5 \pm 0,4$ & $3,5 \pm 0,1$ & $4,8 \pm 0,2$ \\
\hline & C $18: 3$ & $2,4 \pm 0,4$ & $6,8 \pm 0,1$ & $<0,4$ \\
\hline
\end{tabular}

${ }^{1}$ Média de 2 determinações e desvio padrão.

Tabela 2. Compostos polares, ésteres metílicos de ácidos graxos polares e suas frações, polímeros e monômeros oxidados (g.100 $\mathrm{g}^{-1}$ do óleo/gordura) em gordura vegetal parcialmente hidrogenada, óleo de soja e óleo de palma, aquecidos a $180{ }^{\circ} \mathrm{C}$ por 25 horas, provenientes de experimentos de frituras de batatas.

\begin{tabular}{|c|c|c|c|c|}
\hline & \multirow[t]{3}{*}{ Compostos polares (\%) } & \multicolumn{3}{|c|}{ Ácidos graxos polares (\%), m/m } \\
\hline & & \multirow[t]{2}{*}{ Total } & \multicolumn{2}{|c|}{ Frações } \\
\hline & & & Polímeros & Monômeros oxidados \\
\hline \multicolumn{5}{|l|}{ Gordura vegetal } \\
\hline $1^{\circ}$ experimento & 44,1 & 18,6 & 11,2 & 7,4 \\
\hline $2^{\circ}$ experimento & 32,5 & 10,0 & 5,8 & 4,2 \\
\hline \multicolumn{5}{|l|}{ Óleo de soja } \\
\hline $1^{\circ}$ experimento & 20,8 & 7,4 & 4,2 & 3,2 \\
\hline $2^{\circ}$ experimento & 42,6 & 13,9 & 9,2 & 4,7 \\
\hline \multicolumn{5}{|l|}{ Óleo de palma } \\
\hline $1^{\circ}$ experimento & 34,8 & 11,5 & 6,1 & 5,4 \\
\hline $2^{\circ}$ experimento & 41,0 & 13,3 & 7,3 & 6,0 \\
\hline
\end{tabular}


formados os correspondentes ácidos saturados que são claramente diferenciados por sua polaridade. Por conseqüência, os cromatogramas das amostras analisadas foram muito similares e só se diferenciaram pelas quantidades relativas dos distintos picos em relação ao padrão interno.

A Tabela 3 apresenta os valores obtidos de Compostos Polares (CP) e de ésteres metílicos de monômeros oxidados (g.100 $\mathrm{g}^{-1}$ do óleo/gordura); e os valores de ésteres metílicos dos ácidos graxos dos grupos dos monoepoxiácidos, monocetoácidos e monohidroxiácidos (mg/g do óleo/gordura) nas três

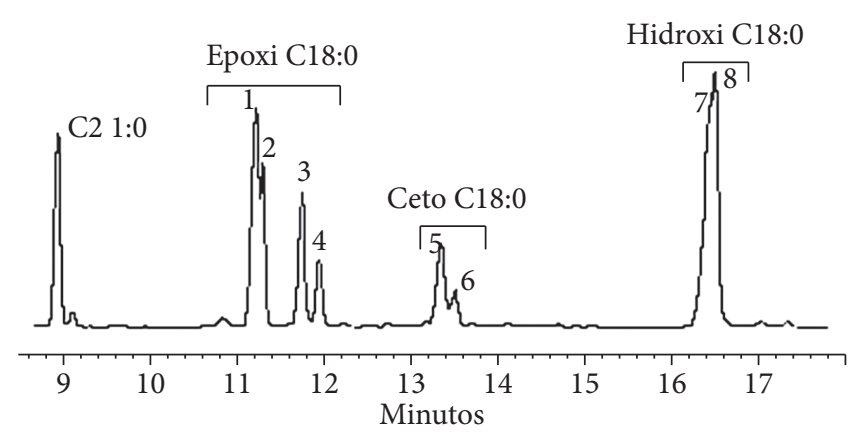

Figura 1. Parte significativa do gráfico da análise cromatográfica a gás dos EMAG polares, incluindo o pico do padrão interno, éster metílico do ácido heneicosanóico (C21:0), com a região dos grupos: monoepoxiácidos (Epoxi C18:0), monocetoácidos (Ceto C18:0) e monohidroxiácidos (Hidroxi C18:0) provenientes da gordura de soja parcialmente hidrogenada aquecida a $180^{\circ} \mathrm{C}$ por 25 horas, oriunda de experimentos de fritura descontínua de batatas. 1, trans 9,10-epoxiestearato de metila; 2, trans 12,13-epoxiestearato de metila; 3, cis 9,10-epoxiestearato de metila; 4, cis 12,13-epoxiestearato de metila; 5, 9 cetoestearato de metila; 6, 13-cetoestearato de metila; 7, 9-hidroxiestearato de metila; 8, 13-hidroxiestearato de metila. Condições cromatográficas: coluna de alta resolução de sílica fundida com fase estacionária de polietilenoglicol, nas dimensões de $60 \mathrm{~m}$ de comprimento; 0,25 mm de diâmetro interno e $0,25 \mu \mathrm{m}$ de espessura de fase estacionária temperatura da coluna: $200{ }^{\circ} \mathrm{C}$ ( 2 minutos $) / 2{ }^{\circ} \mathrm{C} /$ minuto $/ 240{ }^{\circ} \mathrm{C}$ (30 minutos); temperatura do detector e do injetor: $250^{\circ} \mathrm{C}$; fluxo do gás carreador $\left(\mathrm{H}_{2}\right): 1,0 \mathrm{~mL} /$ minuto; razão de divisão de fluxo: 40,0:1; fluxo do gás auxiliar $\left(\mathrm{N}_{2}\right)$ : 45,0 mL/minuto; fluxo do $\mathrm{H}_{2}: 40,0 \mathrm{~mL} /$ minuto; fluxo do ar sintético: 450,0 mL/minuto; volume injetado da amostra: $1,0 \mu \mathrm{L}$. amostras estudadas. Observa-se que a formação dos monômeros oxidados e dos três grupos, monoepoxiácidos, monocetoácidos e monohidroxiácidos, aumentaram com o aumento do nível de degradação (compostos polares) dos óleos/gordura. Também se observa que, para todas as amostras, os níveis de monoepoxiácidos e de monohidroxiácidos foram encontrados em maiores concentrações, e similares entre si, do que os níveis de monocetoácidos; e para as amostras com o mesmo nível de degradação, a gordura vegetal e o óleo de palma apresentaram maiores concentrações de monoepoxiácidos, monocetoácidos e monohidroxiácidos do que o óleo de soja. Estes resultados estão de acordo, para os teores de monoepoxiácidos, aos de Velasco et al. (2004a), que encontraram de 4,29 a 14,24 mg.g ${ }^{-1}$ em óleo de oliva, e de 5,10 a 9,44 mg. g $^{-1}$ em óleo de girassol, termoxidados a $180^{\circ} \mathrm{C}$ por 5,10 e 15 horas; e de 3,37 a 14,42 mg.g ${ }^{-1}$ em óleos e gorduras usados em frituras de restaurantes e lanchonetes da Espanha. Também verificaram que maiores quantidades de monoepoxiácidos foram formadas nos óleos/gorduras monoinsaturados do que nos poliinsaturados.

Em nosso estudo, para as amostras com níveis de compostos polares similares e acima do valor de rejeição, foram obtidos valores que correspondem à porcentagem na fração dos ácidos graxos de monômeros oxidados, de monoepoxiácidos: 10,8; 8,8 e 13,7, respectivamente, em gordura vegetal, óleo de soja e óleo de palma; de monocetoácidos: 5,8; 4,1 e 6,3, respectivamente, em gordura vegetal, óleo de soja e óleo de palma; de monohidroxiácidos: 11,8; 8,8 e 13,7, respectivamente, em gordura vegetal, óleo de soja e óleo de palma.

Com o objetivo de se obter uma estimativa do teor dos monoepoxiácidos, monocetoácidos e monohidroxiácidos em batatas fritas preparadas nos óleos/gordura do estudo, as seguintes etapas foram realizadas: a fração de lipídios das batatas fritas preparadas nos óleos/gordura do estudo foi extraída e seu teor determinado. Os valores obtidos ( $\mathrm{g} .100 \mathrm{~g}^{-1}$ de batata) são apresentados na Tabela 4 .

Para saber se os monômeros oxidados presentes no meio de fritura migraram para a batata frita e em que quantidades, o teor deste grupo de substâncias foi determinado nestes óleos/gordura utilizados no $1^{\circ}$ experimento de fritura, provenientes da fritadeira e das batatas fritas. Os valores obtidos

Tabela 3. Compostos polares e ésteres metílicos de monômeros oxidados (g. $100 \mathrm{~g}^{-1}$ do óleo/gordura); e ésteres metílicos de monoepoxiácidos (EPOXI), monocetoácidos (CETO) e monohidroxiácidos (HIDROXI) (mg.g $\mathrm{g}^{-1}$ do óleo/gordura) em gordura vegetal parcialmente hidrogenada, óleo de soja e óleo de palma, aquecidos a $180^{\circ} \mathrm{C}$ por 25 horas, provenientes de fritura descontínua de batatas.

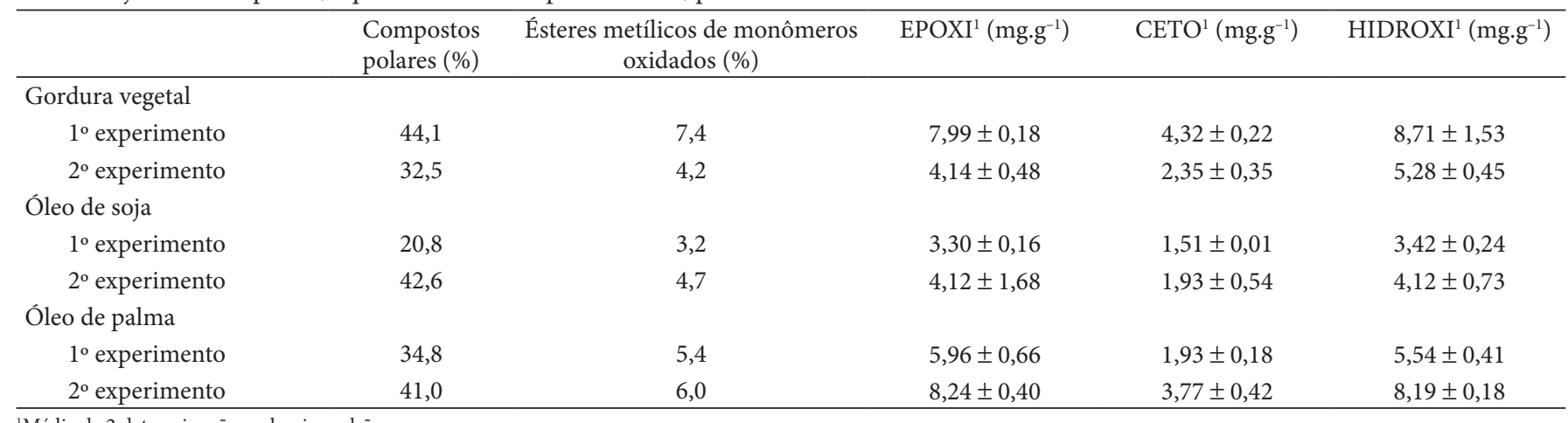

${ }^{1}$ Média de 2 determinações e desvio padrão. 
Tabela 4. Compostos polares (CP) (g.100 g-1 do óleo/gordura); lipídios (g. $100 \mathrm{~g}^{-1}$ de batata frita) e ésteres metílicos de monoepoxiácidos (EPOXI), monocetoácidos (CETO) e monohidroxiácidos (HIDROXI) mg.100 g-1 de batatas fritas preparadas em gordura vegetal parcialmente hidrogenada, óleo de soja e óleo de palma aquecidos a $180^{\circ} \mathrm{C}$ por 25 horas, provenientes de fritura descontínua de batatas.

\begin{tabular}{|c|c|c|c|c|c|}
\hline & $\begin{array}{c}\mathrm{CP} \\
\text { (g.100 g-1 do óleo) }\end{array}$ & $\begin{array}{c}\text { Lipídios } 1 \\
\text { (g.100 g-1 de batata) }\end{array}$ & $\begin{array}{c}\text { EPOXI }^{3} \\
\text { (mg.100 g }{ }^{-1} \text { de batata) }\end{array}$ & $\begin{array}{c}\text { CETO }^{3} \\
\text { (mg.100 g }{ }^{-1} \text { de batata) }\end{array}$ & $\begin{array}{c}\text { HIDROXI }^{3} \\
\text { (mg.100 g-1 de batata) }\end{array}$ \\
\hline \multicolumn{6}{|l|}{ Gordura vegetal } \\
\hline $1^{\circ}$ experimento & 44,1 & $6,6 \pm 1,3$ & 52,73 & 28,51 & 57,49 \\
\hline $2^{\circ}$ experimento & 32,5 & $6,6^{2}$ & 27,32 & 15,51 & 34,85 \\
\hline \multicolumn{6}{|l|}{ Óleo de soja } \\
\hline $1^{\circ}$ experimento & 20,8 & $8,2 \pm 1,3$ & 27,06 & 12,38 & 28,04 \\
\hline $2^{\circ}$ experimento & 42,6 & $8,2^{2}$ & 33,78 & 15,83 & 33,78 \\
\hline \multicolumn{6}{|l|}{ Óleo de palma } \\
\hline $1^{\circ}$ experimento & 34,8 & $8,2 \pm 0,9$ & 48,87 & 15,83 & 45,43 \\
\hline $2^{\circ}$ experimento & 41,0 & $8,2^{2}$ & 67,57 & 30,91 & 67,16 \\
\hline
\end{tabular}

${ }^{1}$ Média de 2 determinações e desvio padrão; ${ }^{2}$ não analisado, considerado o teor de lipídios do $1^{\circ}$ experimento; e ${ }^{3}$ valores obtidos através de cálculos a partir de dados de análises do estudo.

(g.100 $\mathrm{g}^{-1}$ do óleo/gordura) dos óleos/gordura da fritadeira e das batatas fritas foram respectivamente, 14,9 e 15,8, para a gordura vegetal; 6,8 e 7,4, para o óleo de soja; e 11,4 e 11,7, para o óleo de palma. Estes resultados mostraram que os monômeros oxidados formados nos óleos/gordura da fritadeira migraram em quantidades similares para as batatas. Dados obtidos de estudos relatados em artigo de Dobarganes, Márquez-Ruíz e Velasco (2000) demonstraram que os compostos polares migram em quantidades similares do óleo da fritadeira para batatas fritas.

Finalmente, através de cálculos, a partir de resultados de teores de lipídios extraídos das batatas fritas (Tabela 4) e de concentrações dos ésteres metílicos dos monoepoxiácidos, monocetoácidos e monohidroxiácidos dos óleos/gordura das fritadeiras (Tabela 3), foram obtidos teores em mg que são apresentados na Tabela 4, nas faixas de 27,06 a 67,57; 12,38 a 30,91 e 28,04 a 67,16, respectivamente, de monoepoxiácidos, monocetoácidos e monohidroxiácidos, em $100 \mathrm{~g}$ de batatas fritas, que foram preparadas nos óleos/gordura do estudo com níveis de compostos polares na faixa de 20,8 a 44,1\%.

\section{Conclusões}

Conclui-se que nas condições deste estudo, os óleos e gorduras monoinsaturados apresentam maior tendência à formação de monoepoxiácidos, monocetoácidos e monohidroxiácidos e menor tendência à formação de polímeros do que óleos e gorduras poliinsaturados.

E que para os três tipos de amostras estudadas, os polímeros são formados em maior quantidade do que os monômeros oxidados. E os grupos de monoepoxiácidos, monocetoácidos e monohidroxiácidos constituem quantitativamente uma fração muito importante dos monômeros oxidados, sendo os monoepoxiácidos e os monohidroxiácidos as principais substâncias.

\section{Agradecimentos}

Eliana Rodrigues Machado agradece à Coordenação de Aperfeiçoamento de Pessoal de Nível Superior (CAPES), pela bolsa de estágio de doutoramento recebida e ao Instituto de la Grasa - do Conselho Superior de Pesquisas Científicas de Sevilha, Espanha, onde o trabalho foi realizado.
Os autores agradecem também à Sra. Mercedes Gimenez pela assistência e ao Grupo Agropalma pela doação do óleo de palma.

\section{Referências bibliográficas}

AOAC - ASSOCIATION OF OFFICIAL ANALYTICAL CHEMISTS. Official methods of analysis of AOAC International. $17 \mathrm{ed}$. Maryland, USA: AOAC International, 2003. 2v.

BERDEAUX, O.; MÁRQUEZ-RUÍZ, G.; DOBARGANES, M. C. Characterization, quantitation and evolution of monoepoxy compounds formed in model systems of fatty acid methyl esters and monoacid triglycerides heated at high temperature. Grasas y Aceites, v. 50, n. 1, p. 53-59, 1999.

BRASIL. ANVISA. Agência Nacional de Vigilância Sanitária. Resolução RDC n² 270, de 22 de setembro de 2005. Aprova o "Regulamento Técnico para óleos vegetais, gorduras vegetais e creme vegetal". Diário Oficial da República Federativa do Brasil, Brasília, DF, 23 set. 2005. Disponível em: <http://www.anvisa.gov.br/e-legis/> Acesso em: 14 maio 2006.

CHANG, S. S.; PETERSON, R. J.; HO, C. Chemical reactions involved in the deep-fat frying of foods. Journal of the American Oil Chemists' Society, v. 55, n. 10, p. 718-727, 1978.

DANA, D.; SAM SAGUY, I. Frying of nutritious foods: obstacles and feasibility. Food Science Technology Research, v. 7, n. 4, p. 265-279, 2001.

DOBARGANES, M. C.; MÁRQUEZ-RUÍZ, G.; VELASCO, J. Interations between fat and food during deep-frying. European Journal of Lipid Science and Technology, v. 102, n. 8-9, p. 521-528, 2000.

DOBARGANES, M. C.; PÉREZ-CAMINO, M. C.; MÁRQUEZ-RUÍZ, G. Fatty acid composition: a useful tool for the determination of alteration level in heated fats. Revue Française des Corps Gras, v. 35, n. 2, p. 67-70, 1988.

FRANKEL, E. N. Frying fats. In: Lipid oxidation. Dundee, U.K.: Oil Press, 1998. p. 227-248.

GREENE, J. F. et al. Toxicity of epoxy fatty acids and related compounds to cells expressing human soluble epoxide hydrolase. Chemical Research in Toxicology, v. 13, n. 4, p. 217-226, 2000.

IUPAC - INTERNATIONAL UNION OF PURE AND APPLIED CHEMISTRY. Standard methods for the analysis of oils, fats and derivatives. 7 ed. Oxford: Pergamon Press, 1992. supl. 1. 
JORGE, N. Estudo do comportamento do óleo de girassol e do efeito do dimetil polisiloxano em termoxidação e frituras. Campinas, 1996. Tese - (Doutorado em Tecnologia de Alimentos), Universidade de Campinas - Unicamp.

JORGE, N. et al. Influence of Dimethylpolysiloxane Addition to Edible Oils: Performance of Sunflower Oil in Discontinuous and Continuous Laboratory Frying. Grasas y Aceites, v. 47, n. 1-2, p. 20-25, 1996

KOSAKA, K. et al. Leukotoxin, a linoleate epoxide: its implication in the late dealth of patients with extensive burns. Molecular and Cellular Biochemistry, v. 139, n. 2, p. 141-148, 1994.

MARMESAT, S. Comportamiento de aceites de girasol con distinta composición en ácidos grasos a temperatura elevada: formación de nuevos compuestos e influencia de los antioxidantes naturales. Sevilla, 2007. Tese - (Doutorado em Química) - Universidad de Sevilla.

MÁRQUEZ-RUÍZ, G.; DOBARGANES, M. C. Assessments on digestibility of oxidized compounds from $\left[1-{ }^{14} \mathrm{C}\right]$ linoleic acid using a combination of chromatographic techniques. Journal of Chromatography B: Biomedical Sciences and Applications, v. 675, n. 1, p. 1-8, 1995.

MÁRQUEZ-RUíZ, G.; GUEVEL, G.; DObARGAnES, M. C. Application of chromatographic techniques to evaluate enzymatic hydrolysis of oxidized and polymeric triglycerides by pancreatic lipase "in vitro". Journal of the American Oil Chemists' Society, Champaign, v. 75, n. 2, p. 119-126, 1998.

MÁRQUEZ-RUÍZ, G.; PÉREZ-CAMINO, M. C.; DOBARGANES, M. C. Combination of adsorption and size-exclusion chromatography for the determination of fatty acid monomers, dimmers and polymers. Journal of Chromatography A, v. 514, p. 37-44, 1990.

. Digestibility of fatty acid monomers, dimers and polymers in the rat. Journal of the American Oil Chemists' Society, v. 69, n. 9, p. 930-934, 1992.

MÁRQUEZ-RUIZ, G.; TASIOULA-MARGARI, M.; DOBARGANES, M. C. Quantitation and distribution of altered fatty acids in frying fats. Journal of the American Oil Chemists' Society, v. 72, n. 10, p. 1171-1176, 1995.

MITCHELL, L. A.; MORAN, J. H.; GRANT, D. F. Linoleic acid, cis-epoxyoctadecenoic acids, and dihydroxyoctadecadienoic acids are toxic to $S f-21$ cells in the absence of albumin. Toxicology Letters, v. 126, n. 3, p. 187-196, 2002.
MORAN, J. F. et al. Analysis of the cytotoxic properties of linoleic acid metabolites produced by renal and hepatic $\mathrm{P} 450_{\mathrm{S}}$. Toxicology and Applied Pharmacology, v. 168, n. 3, p. 268-272, 2000.

NAWAR, W. W. Volatile components of the frying process. Grasas $y$ Aceites, v. 49, n. 3-4, p. 271-274, 1998

ROMERO, A. et al. Effect of oil replenishment during deep fat frying of frozen foods in sunflower oil and high-oleic acid sunflower oil. Journal of the American Oil Chemists' Society, v. 75, n. 2, p. 161-167, 1998.

SAM SAGUY, I.; DANA, D. Integrated approach to deep fat frying: engineering, nutrition, health and consumer aspects. Journal of Food Engineering, v. 56, n. 2-3, p. 143-152, 2003.

SCHWARTZ, D. P.; RADY, A. H.; CASTAÑEDA, S. The formation of oxo-and hydroxy-fatty acids in heated fats and oils. Journal of the American Oil Chemists' Society, v. 71, n. 4, p. 441-444, 1994.

TOTANI, Y. et al. Leukotoxin and its diol induce neutrophil chemotaxis through signal transduction different from that of fMLP. European Respiratory Journal, v. 15, n. 1, p. 75-79, 2000.

VELASCO, J. et al. Formation and evolution of monoepoxy fatty acids in thermoxidized olive and sunflower oils and quantitation in used frying Oliz from restaurants and freíd-food outlets. Journal of Agricultural and Food Chemistry, v. 52, n. 14, p. 4438-4443, 2004a.

VELASCO, J. et al. Formation of short-chain glycerol-bound oxidation products and oxidised monomeric triacylglycerols during deepfrying and occurrence in used frying fats. European Journal of Lipid Science and Technology, v. 106, n. 11, p. 728-735, 2004 b.

VELASCO, J. et al. Sensitive and accurate quantitation of monoepoxy fatty acids in thermoxidized oils by gas-liquid chromatography. Journal of Chromatography A, v. 982, n. 1, p. 145-152, 2002.

WILSON, R. et al. Dietary epoxy fatty acids are absorbed in healthy women. European Journal of Clinical Investigation, v. 32, n. 2, p. 79-83, 2002a.

WILSON, R. et al. Dietary hydroxy fatty acids are absorbed in humans: implications for the measurement of "oxidative stress" in vivo. Free Radical Biological \& Medicine, v. 32, n. 2, p. 162-168, 2002 b.

ZHENG, J. et al. Leukotoxin-Diol a putative toxic mediator involved in acute respiratory distress syndrome. American Journal of Respiratory Cell and Molecular Biology, v. 25, n. 4, p. 434-438, 2001. 